This is the accepted version of the article:

Aríñez-Soriano J., Albalad J ., Vila-Parrondo C., Pérez-Carvajal J., Rodríguez-Hermida S., Cabeza A., Juanhuix J., Imaz I., Maspoch D.. Single-crystal and humidity-controlled powder diffraction study of the breathing effect in a metal-organic framework upon water adsorption/desorption. Chemical Communications, (2016). 52. : 7229 - . 10.1039/c6cc02908f.

Available at: https://dx.doi.org/10.1039/c6cc02908f 
Received 00th January 20xx, Accepted 00th January 20xx

DOI: $10.1039 / x 0 \times x 00000 x$

www.rsc.org/

\section{Single-crystal and humidity-controlled powder diffraction study of the breathing effect in a metal-organic framework upon water adsorption/desorption}

Javier Aríñez-Soriano ${ }^{a}$, Jorge Albalad ${ }^{a}$, Christian Vila-Parrondo ${ }^{a}$, Javier Pérez-Carvajala , Sabina Rodríguez-Hermida ${ }^{a}$, Aurelio Cabezab ${ }^{b}$ Jordi Juanhuix ${ }^{c}$, Inhar Imaz*a, and Daniel Maspoch*ad
Herein we report a study on water adsorption/desorptiontriggered single-crystal to single-crystal transformations in a MOF, by single-crystal and humidity-controlled powder X-ray diffraction and water-sorption measurements. We identified a gate-opening effect at a relative humidity of $85 \%$ upon water adsorption, and a gate-closure effect at relative humidity of $55 \%$ to $77 \%$ upon water desorption. This reversible breathing effect between the "open" and the "closed" structures of the MOF involves the cleavage and formation of several coordination bonds.

Research on metal-organic frameworks (MOFs), also known as porous coordination polymers (PCPs), has recently put the spotlight on applications that rely on water-sorption properties. These applications include heat transformation; ${ }^{1-4}$ enhancement of $\mathrm{CO}_{2}$ capture; ${ }^{5-7}$ proton conductivity; ${ }^{8-11}$ air dehumidification; ${ }^{12}$ and water delivery in remote areas. ${ }^{13}$ Among the various MOFs that have shown promising watersorption capabilities ${ }^{2,14}$, the flexible "third-generation" MOFs $^{15-17}$ are very interesting because, upon exposure to water at a very specific gate pressure, they can undergo a reversible change from a "closed" structure to an "open" one. Consequently, these MOFs can exhibit stepwise adsorption of water (usually reflected by an S-shape water-sorption isotherm) or behave as a water-induced switching material, which is useful for applications such as heat transformation, ${ }^{18}$ sensors $^{19}$ and proton conductivity. ${ }^{20-22}$ A clear example of this type of flexible MOF is Al-MIL-53-OH ${ }^{14,23}$, which abruptly takes up water at a relative humidity $(\mathrm{RH})$ of roughly $80 \%$, due to a phase transition from its "closed" structure to its "open" one.

To date, very few studies on the breathing effects induced by water sorption in MOFs have been done, and even fewer studies have explored the single crystal-to-single crystal (SCSC) transformations between the "closed" and "open" structures during water sorption. ${ }^{24,25}$ Knowledge on these phase transitions is important for understanding the pertinent water-sorption mechanisms and for developing more efficient MOFs. Much of the work done so far has focused on investigating SC-SC transformations induced by water in dense
MOFs-namely, to study the reversible transitions between crystalline states with different proton conductivities. ${ }^{20-22}$ Importantly, a case showing a water-induced SC-SC transformation between "closed" and "open" structures was reported by Chen et al., who found a transition between a 5fold interpenetrated network (the "open" or hydrated structure) to a 6-fold interpenetrated network (the "closed" or dehydrated structure). They proved that these reversible transformations involved coordination bond cleavages and formations in which water molecules intervened. ${ }^{25}$ More recently, Morris et al. studied the SC-SC transformation of a flexible MOF by using in situ temperature-controlled singlecrystal diffraction studies. They found that the transition between the hydrated porous phase (which is porous to NO) and the dehydrated non-porous phase involved the reversible breaking and formation of several bonds. ${ }^{26}$ Importantly, neither of these two examples has been investigated in terms of water sorption.

Herein, we report a study on water adsorption/desorptiontriggered SC-SC transformations in a MOF, by single-crystal and humidity-controlled powder X-ray diffraction and watersorption measurements. Specifically, we describe the synthesis of a new flexible $\mathrm{MOF}$, of formula $\left[\mathrm{Mn}_{2}(\mathrm{Gd}-\mathrm{H}-\mathrm{DOTA}\right.$ $\left.4 \mathrm{AmP})\left(\mathrm{H}_{2} \mathrm{O}\right)_{7}\right] \cdot 21 \mathrm{H}_{2} \mathrm{O}$ (1) [where $\mathrm{Gd}-\mathrm{H}_{8}$-DOTA-4AmP is $\mathrm{Gd}(\mathrm{III})$ 1,4,7,10-tetraazacyclododecane-1,4,7,10-

tetraacetamidomethylene phosphonic acid (Fig. 1a)], ${ }^{27}$ which exhibits an S-shape (Type V) ${ }^{28,29}$ water isotherm. It abruptly takes up water at a $\mathrm{RH}$ of $85 \%$, reaching its total water uptake of $0.4 \mathrm{~g}_{\text {water }} \cdot \mathrm{g}^{-1}$ at a $\mathrm{RH}$ of $95 \%$. We used single-crystal X-ray diffraction (SCXRD) and humidity controlled powder X-ray diffraction (PXRD) measurements to determine that the water adsorption/desorption mechanism in $\mathbf{1}$ involves an SC-SC transition between two different phases: 1-op (1-open pore) and 1-cp (1-closed pore). To our knowledge, this is the firstever reported use of humidity-controlled PXRD measurements on a flexible MOF to understand its water-sorption behaviour in terms of SC-SC transition.

\footnotetext{
a. Catalan Institute of Nanoscience and Nanotechnology (ICN2), CSIC and The Barcelona Institute of Science and Technology, Campus UAB, Bellaterra, 08193 Barcelona, Spain.

b. Dpto Química Inorgánica, Cristalografía y Mineralogía, Campus de Teatinos $s / n$ Universidad de Málaga, 29071 Málaga, Spain.

c. ALBA Synchrotron, 08290 Cerdanyola del Vallès, Barcelona, Catalonia, Spain.

d. Institució Catalana de Recerca i Estudis Avançats (ICREA), 08100 Barcelona, Spain.

† Footnotes relating to the title and/or authors should appear here.

Electronic Supplementary Information (ESI) available: The experimental section TGA, PXRD, and water sorption measurements. CCDC 1471149 (1-op) and CCDC 1471150 (1-cp). See DOI: 10.1039/x0xx00000x
} 
a)

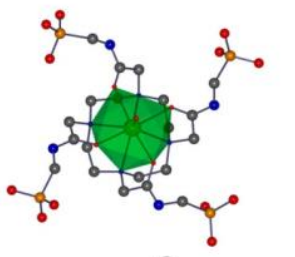

b)
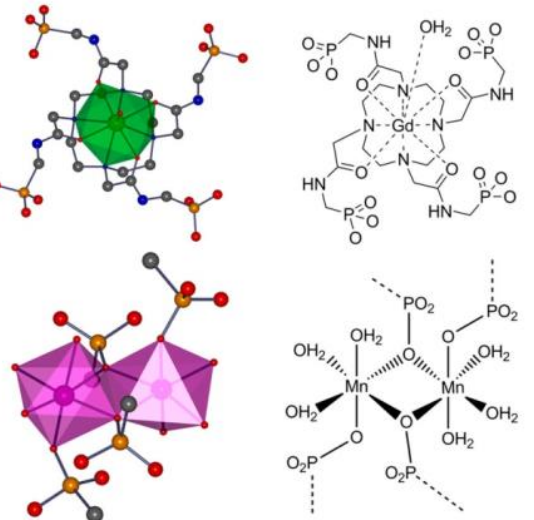

c)

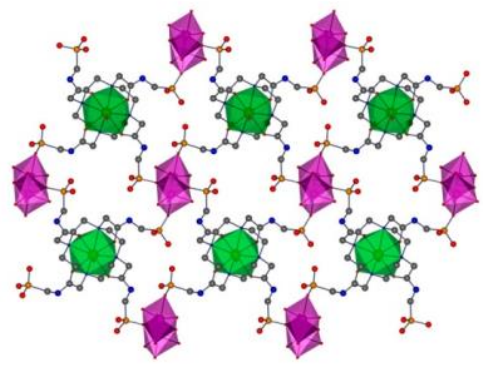

Fig. 1 Crystal structure of 1-op. (a) Coordination environment of Gd-H-DOTA4AmP. (b) Representations of the $\left[\mathrm{Mn}_{2}\left(\mathrm{PO}_{3} \mathrm{R}\right)_{4}\left(\mathrm{H}_{2} \mathrm{O}\right)_{6}\right]$ binuclear building unit. (c) View of a coordination layer along the $b$-axis. Colour code: $\mathrm{Gd}$, green; $\mathrm{Mn}$, pink; $\mathrm{P}$, orange; $\mathrm{O}$, red; $\mathrm{N}$, blue; and $\mathrm{C}$, grey. $\mathrm{H}$ atoms have been omitted for clarity.

Crystals of 1-op suitable for SCXRD were obtained from the reaction of $\mathrm{Gd}-\mathrm{H}_{8}$-DOTA-4AmP and manganese acetate tetrahydrate in water at room temperature for 10 days (yield: $80 \%$ ). The structure of $1-0 p$ was resolved, and refined in the monoclinic space group $P 2_{1} / c$, revealing the formation of a 2-D network of formula $\left[\mathrm{Mn}_{2}(\mathrm{Gd}-\mathrm{H}-\mathrm{DOTA}-4 \mathrm{AmP})\left(\mathrm{H}_{2} \mathrm{O}\right)_{7}\right] \cdot 21 \mathrm{H}_{2} \mathrm{O}$. The basic unit of 1-op is a binuclear unit of formula $\left[\mathrm{Mn}_{2}\left(\mathrm{PO}_{3} \mathrm{R}\right)_{4}\left(\mathrm{H}_{2} \mathrm{O}\right)_{6}\right]$, in which the two $\mathrm{Mn}(\mathrm{II})$ ions are bridged by two $\mathrm{O}$ atoms of two phosphonate groups (Fig. 1b). Both coordinated to three $\mathrm{O}$ atoms of phosphonate groups and to three water molecules. In this structure, each binuclear unit is connected to four Gd-H-DOTA-4AmP linkers and each Gd-HDOTA-4AmP linker is connected to four binuclear $\mathrm{Mn}$ (II) units, creating layers extending along the $a c$ plane (Fig. 1c). These layers show a corrugated conformation and stack up along the $b$-axis, forming 1-D channels that run along the $a$-axis (Fig. 2). The channels have dimensions of approximately $14.8 \AA \times 9.5 \AA$, affording an estimated solvent-accessible void volume of 2,657 $\AA^{3}$, which represents $45 \%$ of the total cell volume $\left(5,958 \AA^{3}\right)$ of 1-op. These channels are filled with 21 guest water molecules per formula unit, as confirmed by elemental analysis and thermogravimetric (TGA) analysis (Table S2 and Fig. S1, ESIt).

Interestingly, single crystals of 1-op underwent structural transformations when they were exposed to a dry environment $(\mathrm{RH}<40 \%)$ for 8 hours. SCXRD performed on the resulting crystals revealed the formation of a new phase, of formula $\left[\mathrm{Mn}_{2}\left(\mathrm{Gd}-\mathrm{H}\right.\right.$-DOTA-4AmP) $\left.\left(\mathrm{H}_{2} \mathrm{O}\right)_{7}\right] \cdot 5 \mathrm{H}_{2} \mathrm{O}$ (1-cp), which crystallises in the monoclinic space group $\mathrm{C2} / \mathrm{c}$. 1-cp is also formed of coordination layers made of binuclear $\mathrm{Mn}$ (II) units bridged by Gd-H-DOTA-4AmP linkers. However, compared to 1-op, 1-cp showed drastically reduced cell volume [compare $5,958 \AA^{3}$ (1-op) to 4,335 $\AA^{3}$ (1-cp); $27 \%$ reduction), and especially, reduced solvent-accessible volume (from 2,657 $\AA^{3}$ (1-op) to $682 \AA^{3}$ (1-cp); 74\% reduction). As expected, this reduction makes 1-cp almost non-porous to $\mathrm{N}_{2}\left(\mathrm{~S}_{\mathrm{BET}}=30 \mathrm{~m}^{2} \cdot \mathrm{g}\right.$ 1) and $\mathrm{CO}_{2}$ (Fig. S3, ESIt). This reduction is a direct consequence of the transition between the corrugated conformation of the coordination layers in 1-op to a flatter conformation in 1-cp. This change leads to closer packing between the coordination layers along the $b$-axis $[b$-axis is reduced from $19.8 \AA$ (1-op) to $14.5 \AA$ (1-cp)], thereby closing the $1 \mathrm{D}$ channels (Fig. 2). This dense packing means that, whilst there is no direct hydrogen bonding between the corrugated layers of 1-op, the closest layers in 1-cp form two direct hydrogen bonds between the $\mathrm{O} 3$ atom of the phosphonate group and the $\mathrm{Mn}(\mathrm{II})$-bound water molecule $\mathrm{O} 3 \mathrm{~W}$ (O3W...03, $2.83 \AA$ A) and the $\mathrm{O} 7$ atom of the phosphonate group and $\mathrm{Gd}(\mathrm{III})$ -
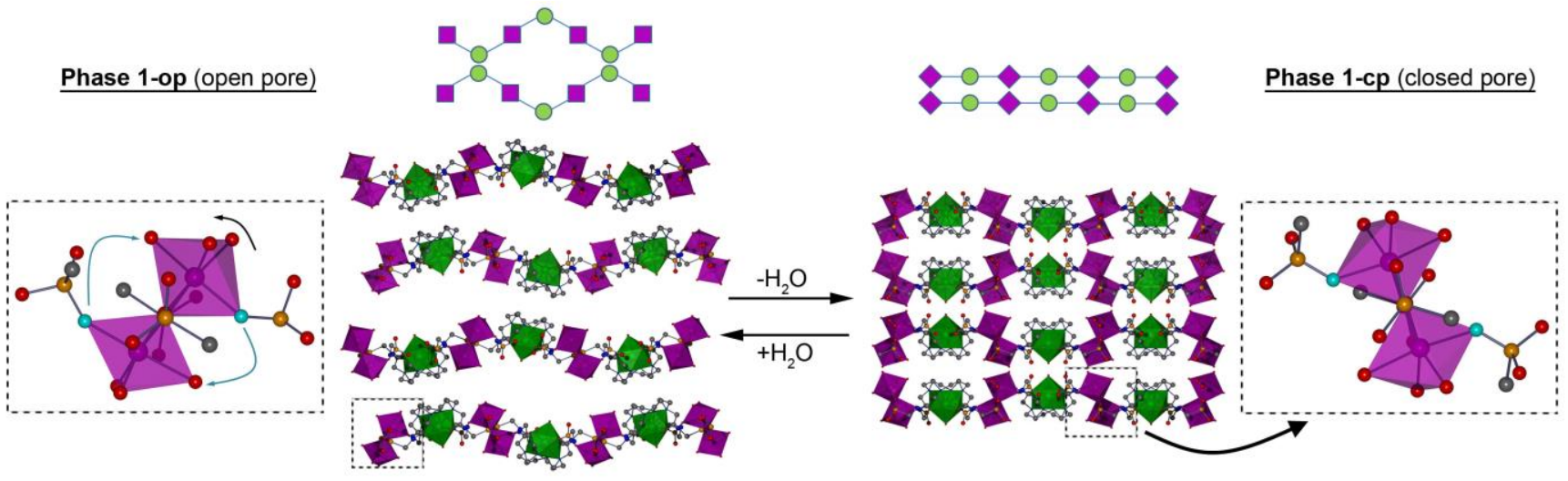

\begin{abstract}
Fig. 2 Schematic representations and views of (top,left) the corrugated coordination layers of 1-op and (top,right) the flatter coordination layers of 1-cp along the $a$-axis. Note that the corrugated layers define the 1D channels, whereas the flat layers close them. (bottom,left) Detail of the Mn(II) binuclear subunit in 1-op showing the cleavage/formation of coordination bonds (blue arrows) and the rotation of the subunit (black arrow) during the phase transition. (bottom, right) View of the resulting binuclear subunit in 1-cp. Colour code: $\mathrm{Gd}$, green; $\mathrm{Mn}$, pink; $\mathrm{P}$, orange; $\mathrm{O}$, red; $\mathrm{N}$, blue; and $\mathrm{C}$, grey. $\mathrm{H}$ atoms have been omitted for clarity.
\end{abstract}

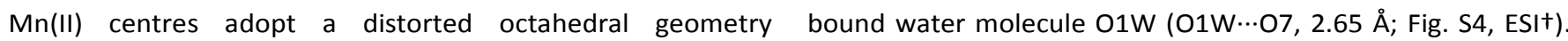




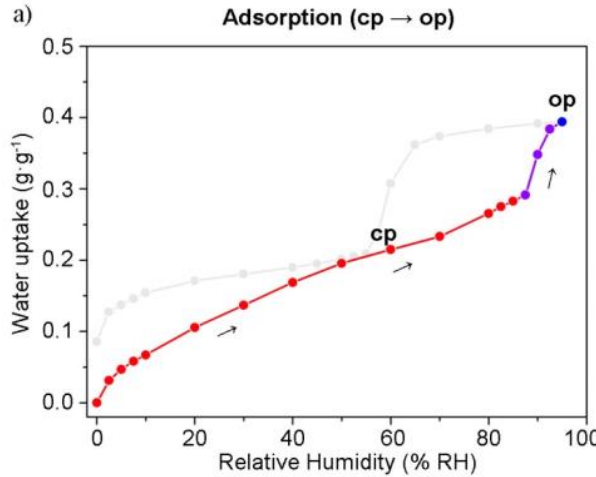

b)

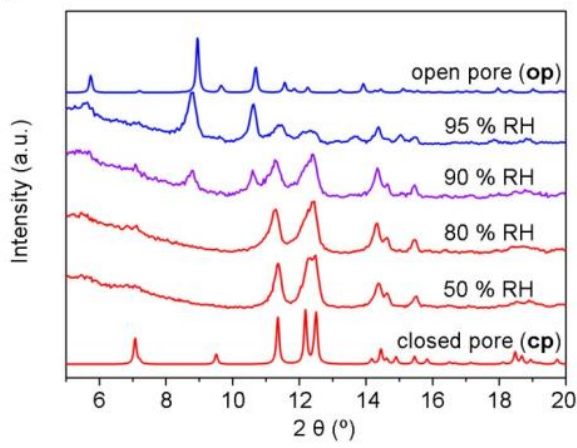

Fig. 3 (a) Adsorption branch of the water isotherm of 1 showing the presence of 1-cp (red), 1-op (blue) and mixed (purple) phases. (b) Humidity-controlled PXRD measurements of 1 at different RH values, showing the presence of 1-cp (red), 1op (blue) and mixed (purple) phases.

Interestingly, it also involves the removal of sixteen guest water molecules, such that only five guest water molecules remain between the layers of 1-cp, as confirmed by elemental analysis and TGA (Table S3 and Fig. S1, ESIt).

A more detailed analysis of the 1-op $\rightarrow \mathbf{1 - c p}$ transformation shows that the transition between the corrugated layers to the flatter layers is promoted by the rotation of the $\mathrm{Mn}$ (II) binuclear building unit around the $a$ axis (Fig. 2). As illustrated in Figure 2, this rotation requires the cleavage and formation of two phosphonate-Mn(II) and two water-Mn(II) coordination bonds per binuclear $\mathrm{Mn}$ (II) unit. Here, we hypothesise that guest water molecules may participate in this ligand exchange mechanism by coordinating to the $\mathrm{Mn}$ (II) ions and forming intermediate species such that two coordinated water molecules would ultimately be replaced with two guest water molecules. ${ }^{25,30}$

To verify the reversibility of this SC-SC transformation, we incubated crystals of 1-cp in water overnight. PXRD analysis of the resulting crystals revealed that 1-op phase is recovered

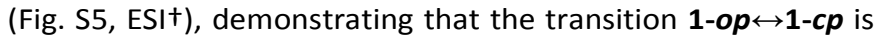
reversible. As 1-op↔1-cp involves the loss and gain of many water molecules, we then investigated whether 1 shows a gate-opening effect upon water sorption. To this end, we combined water-sorption measurements with PXRD analysis in a humidity-controlled environment (Fig. 3 and 4). ${ }^{31,32}$ The collected water isotherm showed different paths between the adsorption and desorption branches. In this isotherm, the water adsorption branch follows a representative type II trend up to a $\mathrm{RH}$ of $85 \%$, in which the water uptake is $0.28 \mathrm{~g}_{\text {water }} \cdot \mathrm{g}_{1}{ }^{-1}$

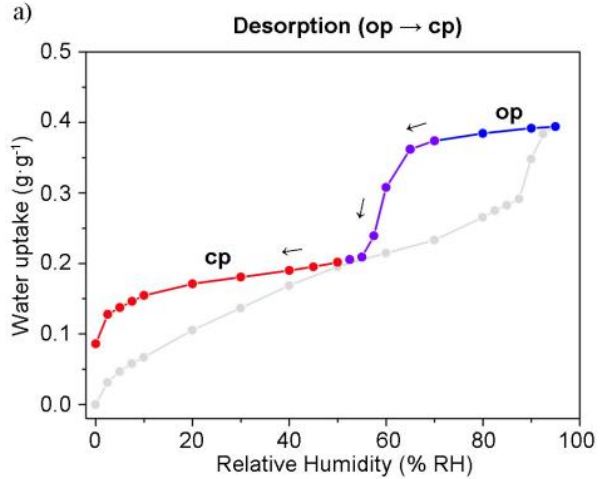

b)

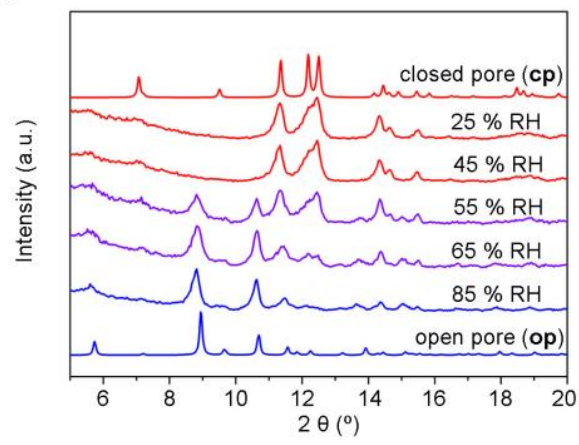

Fig. 4 (a) Desorption branch of the water isotherm of 1 showing the presence of 1 $\boldsymbol{c p}$ (red), 1-op (blue) and mixed (purple) phases. (b) Humidity controlled PXRD measurements of $\mathbf{1}$ at different RH values, showing the presence of 1-cp (red), 1op (blue) and mixed (purple) phases.

or $19 \mathrm{H}_{2} \mathrm{O}$ per formula unit. At this $\mathrm{RH}$, a step appears, changing the trend of the isotherm from type II to type V; behaviour that is characteristic of a gate-opening effect in flexible MOFs (Fig. 3a). ${ }^{33}$ This event increases the water uptake up to $0.40 \mathrm{~g}_{\text {water }} \cdot \mathrm{g}^{-1}$ or $28 \mathrm{H}_{2} \mathrm{O}$ per formula unit at a $\mathrm{RH}$ of $95 \%$. The presence of this step is in agreement with the transition phase 1-cp $\rightarrow \mathbf{1 - o p}$ recorded using humidity-controlled PXRD measurements (Fig. 3b). Indeed, while the characteristic PXRD pattern of 1-cp was observed up to an $\mathrm{RH}$ of $80 \%$, the PXRD pattern at a $\mathrm{RH}$ of $90 \%$ (corresponding to the middle of the step) showed the coexistence of peaks characteristic of both phases. The transition was completed at a RH of $95 \%$, in which the PXRD pattern showed the characteristic pattern of 1-op.

The desorption branch also shows a step in the $\mathrm{RH}$ range from $70 \%$ to $55 \%$ (Fig. 4a). This abrupt desorption of water molecules correlates well with humidity-controlled PXRD measurements of the transition 1-op $\rightarrow \mathbf{1 - c p}$ (Fig. 4b). ${ }^{34}$ Hence, the PXRD pattern at a $\mathrm{RH}$ of $85 \%$ is identical to that of $1-o p$, whereas those patterns collected at RHs of $65 \%$ and $55 \%$ showed the coexistence of peaks characteristic of both phases. Below a RH of $45 \%$, the PXRD pattern is characteristic of 1-cp, as confirmed by the lack of all characteristic peaks of 1-op (e.g. $2 \theta=9.0^{\circ}$ and $10.7^{\circ}$.

We then performed four consecutive cycles of water adsorption/desorption to further analyse the reversibility of the water sorption process (Fig. S6, ESIt). Remarkably, the stepwise trend in the isotherm remained and the maximum uptake $\left(0.40 \mathrm{~g}_{\text {water }} \cdot \mathrm{g}^{-1}\right)$ was not significantly different among the cycles, confirming the stability of the material to water 
sorption/desorption processes The kinetic study of the phase transition 1-cp $\rightarrow \mathbf{1 - o p}$, whereby the 1-cp phase was exposed to an environment having a $\mathrm{RH}$ of $95 \%$ (Fig. S7, ESIt), revealed that the first peaks of the porous phase appeared in the first 15 minutes, whilst the transition could be considered complete after 2.5 hours.

In conclusion, we have described the water-induced reversible SC-SC transformation of a MOF from a "closed" structure to an "open" one. This reversible transformation involves the rupture and formation of several coordination bonds. We have shown that combining water sorption measurements with single-crystal and humidity-controlled powder X-ray diffraction can provide valuable information on any breathing effects that occur during the water adsorption/desorption processes. It is clear that $\mathbf{1}$ shows gate opening at a $\mathrm{RH}$ of $85 \%$, achieving a total water uptake of 0.40 $\mathrm{g}_{\text {water }} \cdot \mathrm{g}^{-1}$. It also shows a large hysteresis, in which the gate closure occurs at an $\mathrm{RH}$ range of $55-70 \%$. Furthermore, we have performed kinetics and recyclability studies, showing a total reversibility between the transition 1-op $\leftrightarrow \mathbf{1 - c p}$ for at least four cycles.

This work was supported by the MINECO-Spain through projects PN MAT2012-30994 and EU FP7 ERC-Co 615954. I.I. and J.A. thank the MINECO for a RyC and FPU predoctoral grant, respectively. A.C. thanks MINECO and Junta de Andalucía through research projects MAT2013-41836-R and P12-FQM-1656, respectively. ICN2 acknowledges the support of the Spanish MINECO through the Severo Ochoa Centres of Excellence Programme, under Grant SEV-2013-0295.

\section{Notes and references}

1 J. Ehrenmann, S. K. Henninger and C. Janiak, Eur. J. Inorg. Chem., 2011, 2011, 471-474.

2 S. K. Henninger, F. Jeremias, H. Kummer and C. Janiak, Eur. J. Inorg. Chem., 2012, 2012, 2625-2634.

3 F. Jeremias, A. Khutia, S. K. Henninger and C. Janiak, J. Mater. Chem., 2012, 22, 10148-10151.

4 M. F. de Lange, K. J. F. M. Verouden, T. J. H. Vlugt, J. Gascon and F. Kapteijn, Chem. Rev., 2015, 115, 12205-12250.

5 E. Soubeyrand-Lenoir, C. Vagner, J. W. Yoon, P. Bazin, F. Ragon, Y. K. Hwang, C. Serre, J.-S. Chang and P. L. Llewellyn, J. Am. Chem. Soc., 2012, 134, 10174-10181.

6 A. O. Yazaydın, A. I. Benin, S. A. Faheem, P. Jakubczak, J. J. Low, R. R. Willis and R. Q. Snurr, Chem. Mater., 2009, 21, 14251430.

7 Y. F. Chen, R. Babarao, S. I. Sandler and J. W. Jiang, Langmuir, 2010, 26, 8743-8750.

8 A. Mallick, T. Kundu and R. Banerjee, Chem. Commun., 2012, 48, 8829-8831.

9 S. C. Sahoo, T. Kundu and R. Banerjee, J. Am. Chem. Soc., 2011, 133, 17950-17958.

10 R. M. P. Colodrero, P. Olivera-Pastor, E. R. Losilla, M. A. G. Aranda, L. Leon-Reina, M. Papadaki, A. C. McKinlay, R. E. Morris, K. D. Demadis and A. Cabeza, Dalton Trans., 2012, 41, 40454051.

11 R. M. P. Colodrero, P. Olivera-Pastor, E. R. Losilla, D.

Hernández-Alonso, M. A. G. Aranda, L. Leon-Reina, J. Rius, K. D. Demadis, B. Moreau, D. Villemin, M. Palomino, F. Rey and A. Cabeza, Inorg. Chem., 2012, 51, 7689-7698.

12 P. Guo, A. G. Wong-Foy and A. J. Matzger, Langmuir, 2014, 30, 1921-1925.
13 H. Furukawa, F. Gándara, Y.-B. Zhang, J. Jiang, W. L. Queen, M. R. Hudson and O. M. Yaghi, J. Am. Chem. Soc., 2014, 136, 4369-4381.

14 J. Canivet, A. Fateeva, Y. Guo, B. Coasne and D. Farrusseng, Chem. Soc. Rev., 2014, 43, 5594-5617.

15 S. Kitagawa and K. Uemura, Chem. Soc. Rev., 2005, 34, 109119.

16 A. Schneemann, V. Bon, I. Schwedler, I. Senkovska, S. Kaskel and R. A. Fischer, Chem. Soc. Rev., 2014, 43, 6062-6096.

17 S. Horike, S. Shimomura and S. Kitagawa, Nat. Chem., 2009, 1, 695-704.

18 C. J. S. K. Henninger, F. Jeremias, J. Ehrenmann, in International Sorption Heat Pump Conference (ISHPC11), Padua, 2011, pp. 415-423.

19 Y. Takashima, V. M. Martínez, S. Furukawa, M. Kondo, S. Shimomura, H. Uehara, M. Nakahama, K. Sugimoto and S. Kitagawa, Nat. Commun., 2011, 2:168 doi:

10.1038/ncomms1170 (2011).

20 S.-S. Bao, N.-Z. Li, J. M. Taylor, Y. Shen, H. Kitagawa and L.-M. Zheng, Chem. Mater., 2015, 27, 8116-8125.

21 M. Sadakiyo, T. Yamada, K. Honda, H. Matsui and H. Kitagawa, J. Am. Chem. Soc., 2014, 136, 7701-7707.

22 S. Tominaka, F.-X. Coudert, T. D. Dao, T. Nagao and A. K. Cheetham, J. Am. Chem. Soc., 2015, 137, 6428-6431.

23 A. Shigematsu, T. Yamada and H. Kitagawa, J. Am. Chem. Soc., 2011, 133, 2034-2036.

24 T. Zheng, J. M. Clemente-Juan, J. Ma, L. Dong, S.-S. Bao, J. Huang, E. Coronado and L.-M. Zheng, Chem. Eur. J., 2013, 19, 16394-16402.

25 J.-P. Zhang, Y.-Y. Lin, W.-X. Zhang and X.-M. Chen, J. Am. Chem. Soc., 2005, 127, 14162-14163.

26 P. K. Allan, B. Xiao, S. J. Teat, J. W. Knight and R. E. Morris, J. Am. Chem. Soc., 2010, 132, 3605-3611.

27 F. K. Kalman, M. Woods, P. Caravan, P. Jurek, M. Spiller, G. Tircsó, R. Kiraly, E. Brücher and A. D. Sherry, Inorg. Chem., 2007, 46, 5260-5270.

28 N. C. Burtch, H. Jasuja and K. S. Walton, Chem. Rev., 2014, 114, 10575-10612.

29 D. Fairen-Jimenez, N. A. Seaton, and Tina Duren, Langmuir 2010, 26, 14694-14699.

30 M. C. Bernini, F. Gándara, M. Iglesias, N. Snejko, E. GutiérrezPuebla, E. V Brusau, G. E. Narda and M. A. Monge, Chem. Eur. J., 2009, 15, 4896-4905.

31 D. Fröhlich, S. K. Henninger and C. Janiak, Dalton Trans., 2014, 43, 15300-15304.

32 F. Jeremias, D. Fröhlich, C. Janiak and S. K. Henninger, RSC Adv., 2014, 4, 24073-24082.

33 S. Brunauer, The Adsorption of Gases and Vapors Vol I Physical Adsorption, Princeton University Press, 1943.

34 T. K. Maji, G. Mostafa, R. Matsuda and S. Kitagawa, J. Am. Chem. Soc., 2005, 127, 17152-17153. 